\title{
FICÇÃO CIENTÍFICA NO BRASIL: O CHOQUE DAS RAÇAS OU O PRESIDENTE NEGRO, DE MONTEIRO LOBATO
}

\author{
Emerson Tin
}

\section{INTRODUÇÃO}

Em uma carta escrita a Godofredo Rangel e enviada de Taubaté a 17 de dezembro de 1905, pode-se encontrar o que seria o primeiro registro da gênese do que viria a ser o "romance americano do ano 2228":

\begin{abstract}
Ando com ideias dumas coisas à Wells, em que entrem imaginação, a fantasia possível e vislumbres do futuro - não o futuro próximo de Julio Verne, futurinho de 50 anos, mas um futuro de mil anos. Vou semear agora essas ideias e deixálas se desenvolverem livremente por dez ou vinte anos - e então limito-me a fazer a colheita, caso a plantação subsista, até lá. Se a terra dos meus canteiros mentais não for propicia a essas sementinhas, então é que não estou destinado a ser o H. G. Wells de Taubaté, e paciência. Ou dou um dia coisa que preste, que esborrache o indígena, ou não dou coisa nenhuma. Ser um Garcia Redondo, que coisa mais quadrada e pífia! (LOBATO, 1964, t.1, p. 112-113)
\end{abstract}

Se se pode confiar no registro dessa carta, o jovem Lobato já aparecia como um entusiasmado leitor de H. G. Wells (1866-1946) - lembre-se que o romance The Time Machine, que é certamente uma das fontes inspiradoras de $O$ choque das raças ou $O$ presidente negro, havia sido publicado em 1895, apenas dez anos antes desse registro epistolar - ou, se não um leitor, um conhecedor da obra do escritor britânico que já começava a circular 
pelo Brasil. Por exemplo, em 24 de janeiro de 1902, a Gazeta de Notícias publicava em suas páginas um longo artigo sobre Wells assinado por S. A. M., em que o escritor era apresentado ao público em comparação com Júlio Verne (1828-1905):

De Wells já houve quem dissesse que era um "Júlio Verne para gente grande”. Seu processo de composição lembra efetivamente, em certos romances, a fatura do célebre escritor francês de universal nomeada. Mas Júlio Verne é mais um vulgarizador, um expositor de ciência amena e facilmente assimilável porque sempre é envolvida por uma ficção atraente. Wells é mais do que isso. [...] Wells tem sobre Júlio Verne este mérito: além da ficção, original e sempre interessante, desperta reflexões e cada um de seus livros nos traz talvez um ensinamento bem maior às vezes do que julgamos. (S. A. M., 1902, p. 1, 2)

Esse entusiasmo se manteria ao longo de sua vida, como se pode ler no artigo "Rondônia" - a respeito do livro homônimo, publicado em 1916, de Edgar Roquette-Pinto (1884-1954) -, incluído no livro Ideias de Jeca Tatu (1919):

O romancista inglês $H$. G. Wells nasceu com três olhos - os dois de toda gente e um terceiro - esperem! - agudíssimo, não se sabe localizado onde, cuja faculdade de devassar o futuro emparelha com a visão profética dos Isaías e Ezequiéis. [...] Do muito relativo às eras porvindouras que Wells entreviu avulta a perspectiva da humanidade em crepúsculo lá para anos que se numeram por centenas de milhares. É na Máquina do Tempo que nos conta isso. (LOBATO, 1964, p. 137-138)

Ou, em outra carta, dirigida de Buenos Aires a Hernani Ferreira e datada de 27 de janeiro de 1947:

A leitura do Wells é indispensável. Não compreendo um intelectual moderno sem muito Wells na cabeça. Sobretudo o da Formação do Mundo. É indispensável para nós mais que para qualquer outra gente, dada a nossa falta de cultura, ou de base científica. (LOBATO, 1986, p. 72)

Não é ocioso lembrar, também, que Lobato viria a traduzir The Shape of Things to Come (1933), de Wells e publicar, em 1940, sob o título de História do Futuro, pela Companhia Editora Nacional, e cuja leitura recomenda enfática e entusiasticamente ao novel romancista Flávio de Campos (1903-1947), em carta de 29 de outubro de 1939:

Demorei para atracar-me com V. porque estava concluindo a tradução de um livro que terás de ler, porque é básico - The Shape of Things to Come, que vamos dar com o título de História do Futuro. Havemos mais tarde de conversar sobre 
este monumento de utopia científica. Toda as utopias anteriores, da de Platão à de Moro, foram apenas filosóficas. (LOBATO, 1986, p. 63)

Ênfase e entusiasmo sobre a obra de Wells que se repetem na resenha que faria do romance do mesmo Flávio de Campos, intitulada "Planalto um romance que prenuncia outro”, incluída em sua Miscelânea:

\begin{abstract}
Os romancistas são os modernos fixadores dos aspectos transitórios da vida. Desenham as almas e os ambientes do caminho. Fazem a verdadeira história da aventura humana no planeta. Preparam os cortes anatômicos necessários aos estudos dos sociólogos a virem. Romance nenhum deixa de ser um documento; na pior hipótese, documento da incapacidade estética do autor. Um gomo inteiro da vida ecológica da França está fixado na "Comédia Humana”, de Balzac. Huxley está hoje fixando o drama da inteligência científica em choque com os encrostamentos da tradição. Wells vai além: transforma-se numa universidade viva e consegue alçar-se à profecia. The Shape of Things to Come realiza o milagre da introdução da matemática na história. Wells soma os algarismos do passado com os do presente e dá os números - o bicho, a dezena, a centena e o milhar do futuro próximo. (LOBATO, 1964, p. 230)
\end{abstract}

Curiosamente, a "fórmula" matemática de futurologia atribuída a Wells era a mesma exposta em seu romance $O$ choque das raças:

É positivamente misterioso o professor Benson e afigura-se-me um mágico que vê através do futuro.

Ri-me da expressão do meu amigo e, qual um filósofo barato, murmurei com superioridade:

- Como pode ver através do que não existe? O futuro não existe...

$\mathrm{O}$ corretor respondeu-me com uma frase que naquele momento não compreendi:

- Não existe, sim, mas vai existir necessariamente. Dois mais dois - é o presente.

A soma quatro é o futuro. (LOBATO, 1926, p. 12-13)

Conforme se sabe, Wells é um dos grandes nomes da ficção científica na passagem do século XIX para o XX, e Lobato, como é possível perceber a partir dos trechos transcritos de sua correspondência e de outros textos, deveria tê-lo como um grande modelo para suas especulações nesse gênero. Quais seriam os traços distintivos da ficção científica?

Pode-se perceber, a partir do próprio nome mais comum que se atribui a esse gênero, que há dois elementos fundamentais nos quais ele se fundamenta: a narração literária, por um lado, representada pelo substantivo "ficção", e o conhecimento científico, por outro, consubstanciado no adjetivo "científica". Harry Shaw, aliás, define-a como um "gênero de narração literária, cujo enredo, tema e cenário se alicerçam, 
duma forma imaginativa, no conhecimento científico e respectivas teorias e especulações" (SHAW, 1982, 208).

Em seu artigo "Máquinas utópicas e distópicas", João Camillo Penna pondera que

a definição da ficção científica foi posta de maneira canônica por Darko Suvin: ficção científica é o relato sobre um novum como espelho analógico, no qual interagem estranhamento e cognição, na construção de um mundo imaginário possível, outro com relação ao do autor / leitor. A differentia especifica da ficção científica a situa em um local ao mesmo tempo distinto e imbricado de / com três territórios afins: a ciência tout court, a narrativa gótica ou fantástica e a invenção técnica. [...] O relato procura situar-nos na pele do protagonista, de forma a nos perguntarmos: "Como você se sentiria e o que poderia ocorrer com você no lugar do protagonista, naquele mundo estranho ao nosso, povoado de seres desconhecidos?" Eis portanto a matriz da definição de Darko Suvin: a ficção científica como "estranhamento cognitivo". (PENNA, 2008, p. 186-188)

Em paralelo a esse "estranhamento cognitivo", tem-se o debruçar-se da ficção científica sobre as transformações pelas quais passa o mundo em que vive o seu autor. Nesse sentido, defende Nelson Marques que,

se levarmos em consideração que a ficção científica, ou mesmo a ficção especulativa, trabalha com qualquer história que coloca como argumento central um mundo em transformação (obviamente envolvendo ciência e tecnologia), podemos perceber a importância e atualidade de temas que sempre atraíram diferentes autores das mais diversas épocas. Trabalhando com mundos imaginários, transformados ou em transformação (mais ainda com a linguagem, as proposições e os argumentos da ciência contemporânea ou particularmente de cada uma das épocas) há um profundo senso de que a história humana é uma realidade contínua e as mudanças fluem do que nós conhecemos dessa realidade. (MARQUES, 2002, p. 47)

Estaria Lobato, dessa maneira, ao produzir a sua ficção científica, destinado a ser o "H. G. Wells de Taubaté"? Boa parte da crítica afirma que não, e chega a ser categórica. André Carneiro, por exemplo, em seu já clássico Introdução ao estudo da "science-fiction", apesar de, reconhecendo o caráter precursor do romance, considerá-lo como "a primeira obra [de ficção científica] de escritor conhecido naqueles tempos", afirma que " $O$ presidente negro, além de fraco literariamente, é um livro racista, contra a raça negra” (CARNEIRO, 1967, 109). Em que pontos consistiria, nesse sentido, a "fraqueza literária" de $O$ presidente negro? 
Nunca me julguei capaz de conduzir um romance até o fim, e no entanto lá o pari em 20 dias. Como é canja escrever um romance!

Disse-o ontem ao Coelho Neto e ele amoitou. (Carta de Monteiro Lobato a Godofredo Rangel, 7 de fevereiro de 1927)

Publicado inicialmente em folhetim, entre os meses de setembro e outubro de 1926, nas páginas do jornal A Manhã, de Mário Rodrigues, o romance seria editado, ainda nesse mesmo ano, pela Companhia Editora Nacional e seria dedicado "a Artur Neiva e Coelho Neto, dois grandes mestres do trabalho, na ciência e nas letras". Até mesmo nessa dedicatória, pode-se ver os dois elementos fundamentais que compõem a ficção científica: de um lado, a narração literária, tendo como padrinho o célebre romancista maranhense Coelho Neto (1864-1934); de outro, o conhecimento científico, representado pelo sanitarista baiano Artur Neiva (1880-1943), com quem Lobato mantinha assídua correspondência. Além disso, vale destacar alguns elementos da estrutura narrativa do romance lobatiano.

O primeiro desses elementos é o narrador. Trata-se de um narrador personagem, Ayrton Lobo, um “inocente”, na definição do erudito professor Benson: "chamo inocente ao homem comum, de educação mediana e pouco penetrado nos segredos da natureza. Empregado no comércio: quer dizer que não teve estudos" (LOBATO, 1926, p. 31). Percebe-se que a escolha do narrador não poderia ser "pior": para um gênero de narrativa que envolveria conhecimento científico, teorias e especulações, elegeu-se um homem comum, nas suas próprias palavras, "lento [...] de espírito" (LOBATO, 1926, p. 33), que não consegue "entender cousa nenhuma" (LOBATO, 1926, p. 42), dotado de "curteza mental" (LOBATO, 1926, p. 54).

Outro elemento a ser destacado é a estratégia narrativa. Narram-se fatos do futuro, que se passariam no remoto ano de 2228. Diferentemente, porém, de uma narrativa como A máquina do tempo, de Wells, em que o seu Viajante do Tempo se desloca, ele mesmo, para o futuro', em $O$

1 "TIME MACHINE - In SF, the mechanism used to transport any person or thing into the past or future. H. G. Well's The Time Machine (N.Y. 1895) provided both the name and plot basis for most time travel vehicles" (SCIENCE FICTION DICTIONARY, 1951, p. 28). 
choque das raças, a máquina do tempo - o "porviroscópio" - não permite o deslocamento no tempo, mas apenas a sua visualização.

Mas não é só. A estrutura narrativa do romance dá-se por camadas, por encaixe: Ayrton Lobo, a partir da morte do professor Benson e da destruição do "porviroscópio" - aparelho que, aliás, o narrador nem sequer chega a ver totalmente em funcionamento ${ }^{2}-$, narra todos os acontecimentos do futuro a partir dos relatos de Miss Jane, por quem nutre uma paixão arrebatadora e na presença de quem se produzia "a ruptura do [...] equilíbrio nervoso" (LOBATO, 1926, p. 35) do narrador. Ou seja, Ayrton Lobo narra a história do choque das raças a partir do relato de Miss Jane e encaixada na narrativa folhetinesca dos seus amores com a jovem, narrativa que culmina com o final cinematográfico no último capítulo, sintomaticamente intitulado "O beijo de Barrymore" em alusão ao ator norte-americano John Barrymore (1882-1942), que, naquele mesmo ano de 1926, estrelava Don Juan, no qual teria beijado, segundo material promocional do filme 3 , 191 mulheres!

Miss Jane, por sua vez, narra-lhe os fatos a partir do que ficou registrado em sua memória de tudo o que teria visto por meio do "porviroscópio". Por fim, não se pode deixar de formular uma última especulação: seria a transmissão do "porviroscópio" totalmente confiável? Em outras palavras, poderia o homem do presente confiar cegamente na mediação da máquina ao transmitir-lhe o futuro? Nesse sentido, entre o leitor e os fatos narrados há pelo menos as seguintes mediações: a) a da máquina (os fatos foram vistos por Miss Jane por meio do "porviroscópio"); b) a da memória (os fatos narrados são aqueles registrados na memória de Miss Jane); c) a da linguagem (Miss Jane narra os fatos ao narrador, Ayrton Lobo).

Como bem observou Maicon Alves Dias,

2 A partir dos trechos seguintes, percebe-se que Ayrton Lobo não chega a ver o porviroscópio funcionando, já que a máquina viria a ser destruída pelo professor Benson: "Escolha, senhor Ayrton. Ontem foi a teoria, hoje começa a ser a prática. Vai estudar uns cortes. Escolha um momento da vida futura que o interessa." (LOBATO, 1926, 79-80)

“Teremos de esperar 17 horas e 54 minutos." (LOBATO, 1926, p. 83)

"Quando te deixei no gabinete com pretexto de concluir um trabalho, iludi-te, ou, melhor, vim fazer um trabalho muito diverso do que poderias supor. Vim destruir a minha descoberta. Queimei toda a papelada relativa e desmontei as peças mestras dos aparelhos. O que resta nenhuma significação possui e não poderá ser restaurado. Desfiz em meia hora o trabalho de toda uma vida. Da minha invenção restam apenas as impressões que te deixou ela na memória. E quando por tua vez morreres, tudo se extinguirá..." (LOBATO, 1926, p. 92)

3 "On 6 August 1926 Don Juan premiered in New York. Promotional material stressed the 191 kisses Barrymore bestowed in the course of the film and his 'Great Lover' image" (MORRISON, 1999, 264). 
o mundo representado no romance $O$ presidente negro é exposto através da linguagem criada por Miss Jane, que é o mundo fantástico, "distante" ealegórico observado através do porviroscópio e, também, o mundo "real”, representado pela linguagem de Ayrton Lobo. Este paralelo entre o presente, que é a realidade burocrática e crítica do Brasil sentenciada pelo narrador Ayrton Lobo, e o futuro, que é a sociedade americana com suas polêmicas discussões e "avanços" colocados de forma alegórica pela personagem Miss Jane, é o mote que vai engendrar o eixo central do romance de Monteiro Lobato. (DIAS, 2009, p. 77)

Se, por um lado, pode-se especular que o romance de Monteiro Lobato nasceu de uma ideia semeada vinte anos antes de sua redação, como registrado em sua carta ao amigo Rangel, pode-se, por outro, dentro da narrativa ficcional, concluir que a ideia do romance surge de uma sugestão de Miss Jane ao narrador:

- Esse choque, disse miss Jane, deu-se no ano 2228 e assumiu tão empolgantes aspectos que reduzido a livro dá uma perfeita novela. Não sei se o senhor Ayrton é literato...

- Já fiz um soneto na idade em que todos desovam sonetos...

- Pois se não é poderá tornar-se. O principal para uma novela é ter o que dizer, estar senhor de um tema na verdade interessante. Ora, eu fornecerei os dados dessa novela e o senhor Ayrton terá oportunidade ótima para apresentar-se ao mundo das letras com um livro que a crítica julgará ficção, embora não passe da simples verdade futura.

A ideia sorriu-me, e todo me lisonjeei com a opinião que miss Jane fazia das minhas capacidades artísticas.

- Quer tentar? insistiu ela. Contar-lhe-ei com a máxima fidelidade o que vai passar-se. De posse desse material, e depois de pessoalmente fazer vários cortes que o ajudem a formar ideia justa do ambiente futuro, atirar-se-á à tarefa. Desde já asseguro uma coisa: sairá novela única no gênero. Ninguém lhe dará nenhuma importância no momento, julgando-a pura obra da imaginação fantasista. Mas um dia a humanidade se assanhará diante das previsões do escritor, e os cientistas quebrarão a cabeça no estudo de um caso, único no mundo, de profecia integral e rigorosa até nos mínimos detalhes.

- Realmente! exclamei. Será romance como os de Wells, porém verdadeiro, o que lhe requintará o sabor. Quanta novidade! (LOBATO, 1926, p. 84-85)

Estão lançadas as bases da ficção científica lobatiana: Ayrton Lobo figuraria como o narrador de uma "perfeita novela", redigida a partir dos dados fornecidos por Miss Jane. E quais seriam os dados? Justamente os relativos ao choque das raças, que, segundo as palavras de Miss Jane, "deuse no ano 2228". É interessante notar como que, para a personagem, por já se constituir em matéria de memória, o choque das raças não é mais fato futuro, a acontecer, mas fato do passado, histórico - daí o emprego do verbo no passado: "deu-se". Nesse sentido, a narrativa lobatiana se coaduna com a definição do gênero exposta por George Mann: 
A ficção científica é uma forma de literatura fantástica que tenta retratar, em termos racionais e realistas, tempos futuros e ambientes que diferem dos nossos. No entanto, mostra estar consciente das preocupações dos tempos em que é escrita e provê um comentário implícito sobre a sociedade contemporânea, explorando os efeitos, materiais e psicológicos, que qualquer tecnologia nova pode ter sobre ela. Quaisquer mudanças que tiverem lugar na sociedade enfocada, e também quaisquer acontecimentos futuros que forem extrapolados, deverão basear-se em uma teoria, científica ou não, encarada em forma comedida e considerada. Os autores de ficção científica usam seus ambientes estranhos e imaginativos como um campo de prova para novas ideias, examinando em forma plena as implicações de qualquer noção que propuserem. (MANN, 2001, p. 6)

Punha-se o romance, então, como campo de prova para novas ideias. Quais seriam elas?

\section{... E DE ARTUR NEIVA}

Felizmente a ciência vai entrando no Brasil - e quanto graças à sua atividade!

País sem ciência, hoje, é país derrotado. (Carta de Monteiro Lobato a Artur Neiva, 20 de junho de 1929)

O nome de Monteiro Lobato ganharia notoriedade a partir de 1914, quando publicara o artigo "Velha Praga", do qual nasceu um dos seus mais famosos personagens: Jeca Tatu. Como se sabe, ali Lobato atribuiria culpa ao Jeca pelo empobrecimento das terras cultiváveis em razão da prática das queimadas, hábito que resultaria da indolência do caboclo. Anos mais tarde, porém, Lobato reveria sua posição e, num mea culpa, concluiria que "O Jeca não é assim: está assim", atribuindo a proverbial preguiça do caboclo às condições sanitárias em que vivia.

Da aproximação de Lobato com expoentes da ciência do período, como Belisário Pena (1868-1939) e Artur Neiva, nasceria uma série de artigos sobre sanitarismo, que seria publicada em livro, em 1918, com o título Problema vital, sob os auspícios da "Sociedade de Eugenia de S. Paulo" e da "Liga Pró-Saneamento do Brasil".

É possível supor que desse contato com Artur Neiva - correspondente contumaz de Lobato e um dos nomes a quem o romancista dedica o livro tenha surgido a ideia do choque das raças nos Estados Unidos do ano 2228. Pode-se perceber ainda, com Marcia Camargos e Vladimir Sacchetta, que 
mais do que um hino em prol da pureza racial, este romance constrói uma metáfora sobre segregação e aculturação. Ao longo do enredo vemos como a comunidade negra é impelida a assumir valores étnicos dos brancos. Em detrimento da sua ascendência africana, consideráveis parcelas de filhos e netos dos ex-escravos submetem-se por vontade própria a um radical processo de despigmentação, tornando-se "horrivelmente" esbranquiçadas. Combatente visceral da imitação dos hábitos e costumes alheios, Lobato defendia a tese de que ignorar as raízes significa converter-se em cópia malsucedida. A despigmentação os descaracteriza como povo, retirando deles um dos seus principais elementos de identidade. Com a autoestima diminuída na pele artificialmente clareada e nos cabelos alisados, o negro reproduz o modelo do branco. Ao abrir mão das suas características físicas, adotando uma feição que não é a sua, ele se converte em elo fragilizado e vulnerável de uma corrente corroída na sua essência. (CAMARGOS, SACCHETTA, in LOBATO, 20o8, p. 18)

\section{Ou, como defende Marisa Lajolo:}

Pode-se, assim, ler em $O$ presidente negro uma grande metáfora das consequências da desculturação de um grupo étnico e, simultaneamente, o grau de solidariedade entre ciência, arte, tecnologia e comunicação, tal como são praticados nas instâncias centrais e que só encontram seu sentido último nas lutas que pelo poder se travam no corpo social e: comunicação, tecnologia, arte e ciência, no caso, serviram para a população branca exterminar a população negra. (LAJOLO, s/d)

\section{Afinal, constitui um juízo muito superficial e simplista pinçar um ou} outro trecho da boca de uma personagem e afirmar que o romance é um "livro racista, contra a raça negra". Há páginas do romance, porém, que lidas sob outra ótica, permitem reconhecer exatamente o contrário:

Descortinou todo o lúgubre passado da raça infeliz. Viu muito longe, esfumado pela bruma dos séculos, o humilde kraal africano visado pelo feroz negreiro branco, que em frágeis brigues vinha por cima das ondas qual espuma venenosa do oceano. Viu o assalto, a chacina dos moradores nus, o sangue a correr, o incêndio a engolir as palhoças. Depois, o saque, o apresamento dos homens pálidos e das mulheres, a algema que lhes garroteava os pulsos, a canga que os metia dois a dois em comboios sinistros tocados a relho para a costa. Viu, como goelas escuras, abrirem-se os porões dos brigues para tragar a dolorosa carne do eito. E recordou o interminável suplício da travessia... Carga humana, coisa, fardos de couro negro com carne vermelha por dentro, A fome, a sede, a doença, a escuridão. Por sobre as cabeças da carga humana, um tabuado. Por cima do tabuado, rumores de vozes. Eram os brancos. Branco queria dizer uma coisa só: crueldade fria...

Viu depois o desembarque. Terra, árvores, sol - não mais como em África. Nada deles, agora - nem a terra, nem as arvores, nem o sol. Caminha, caminha! Se um tropeça, canta-lhe o látego no lombo. Se cai desfalecido, trucidam-no. A caravana marcha, trôpega, e penetra nos algodoais... Viu Jim viçarem luxuriosos 
os algodoais da Virgínia depois que o negro chegou. Além das chuvas havia a regá-los agora o suor africano - suor e sangue.

Viu dois séculos de chicote a lacerar carne e outros dois séculos de lagrimas, de gemidos e lamentosos uivos de dor. E viu a America ir saindo dessa dor, como a pérola, filha do sofrimento do molusco, nasce na concha...

Viu depois a Aurora da noite de duzentos anos: Lincoln. O Branco Bom disse: "Basta!" Ergueu exércitos e das unhas de Jefferson Davis arrancou a pobre carne-coisa.

As algemas caíram dos pulsos mas o estigma ficou. As algemas de ferro foram substituídas pelas algemas morais do pária. O sócio branco negava ao sócio negro a participação de lucros morais na obra comum. Negava a igualdade e negava a fraternidade, embora a Lei, que paira serena acima do sangue, consagrasse a equiparação dos dois sócios.

E viu Jim que Justiça não passava de uma pura aspiração - e que só ha justiça na terra quando a força a impõe.

- "Hei de fazer-me força e impor a justiça", murmurou o grande negro. (LOBATO, 1926, p. 174-175)

Todavia, não apenas em torno de discussões eugênicas constrói-se o romance. O choque das raças é uma ficção especulativa sobre o futuro e, portanto, insere-se numa longa tradição de narrativas que têm por base o deslocamento no tempo: desde a viagem no tempo de Moisés, registrada na Haggada - segundo Jacques Bergier, "a primeira descrição de viagem no tempo encontrada não se acha num conto de ficção científica e não é de nossa época. Acha-se na Haggada, compilação de tradições não jurídicas que faz parte do Talmude" (BERGIER, 2003, 61) -, passando pela já citada Máquina do tempo, de H. G. Wells, até chegar a toda a produção nele inspirada. Lembre-se, nesse passo, o que ponderou Nelson Marques a respeito das viagens no tempo:

Não é gratuito, portanto, que Brian Ash, um autor bem considerado no mundo da ficção científica, coloque como temas importantes e recorrentes nas histórias de ficção científica as viagens no tempo e o encontro de mundos perdidos (passado), mundos paralelos (presente) ou novos mundos (futuro). Opinião semelhante tem André Carneiro, que destaca também as viagens espaciais e as viagens no tempo como temas importantes das histórias de ficção científica (MARQUES, 2002, p. 47).

\section{Nesse sentido, Alexander Meireles da Silva acaba por apontar}

a semelhança entre o romance de Lobato e A Máquina do Tempo, de H. G. Wells, no que se refere ao papel dos produtos do progresso na constituição do tecido social. Neste romance de 1895 , a viagem ao futuro de um cientista vitoriano revela a divisão da humanidade em duas raças distintas: os pacíficos e passivos moradores da superfície chamados de Elóis e os selvagens canibais habitantes do subsolo de nome Morlocks. A representação destes dois lados do homem 
foi considerada uma clara crítica do escritor inglês aos rumos da Revolução Industrial e o que poderia acontecer com o proletariado (os Morlocks) caso continuassem a serem excluídos e explorados pelas classes mais abastadas (os Elóis). A influência das teorias de Darwin também está presente no retrato dos Elóis e dos Morlocks como resultado da evolução de seus ambientes. Este princípio científico foi deturpado pelas classes dirigentes na Europa e no Brasil para igualar pobreza a marginalidade. (SILVA, 2008, p. 276-277)

\section{A VIAGEM NO TEMPO CONTINUA...}

A esperança depositada no romance por Lobato era imensa: por meio dele, pretendia não somente consolidar seu sucesso literário no Brasil, mas também lançar-se no mercado editorial norte-americano, o que acabou não ocorrendo. De início, entusiasmado com o romance, escreveria ao amigo Artur Neiva, pedindo-lhe vênia para a dedicatória:

Tirei o mês de julho para escrever um romance americano que me pediu um publisher de lá. Fi-lo em 20 dias, ao correr da pena, e aproveitando uma velha ideia que um dia lhe comuniquei.

Quero dedicar esse livro ao Dr., mas antes disso desejo a sua opinião. Vou mandar-lhe uma cópia logo que o copista me entregue as que lhe pedi. Peçolhe que leia e sugira-me mais alguma coisa aproveitável. Vai sair em português, francês, alemão, espanhol e inglês ao mesmo tempo. Hei de dar uma tacada no único bicho que há hoje no mundo: E. U. (TIN, 2007, p. 453)

Após a publicação em livro, essa imensa esperança aparece registrada, por exemplo, em carta ao cunhado Heitor de Morais no Natal de 1926 (publicada em Cartas escolhidas):

Minhas esperanças estão todas na América. Mas o "Choque" só em fins de janeiro estará traduzido para o inglês, de modo que só lá pelo segundo semestre verei dólares. Mas os verei eà beça, já não resta a menor dúvida. [...] O “Choque” já saiu em S. Paulo, mas ainda não o vi. Esse livro vai mudar o rumo da minha vida. O consulado americano está interessadíssimo nele. Viva o talento, Seu Heitor. (LOBATO, 1964, t.1, p. 200)

Tempos depois, acabaria reconhecendo a falta de adequação de seu livro ao público norte-americano em carta à amiga Iainha Pereira Gomes:

Estou com enredo de fita apresentado à Metro Goldwin, dois livros de crianças apresentados a dois diretores, e com o Choque encalhado como sempre. $\mathrm{O}$ curioso é que esse livro foi traduzido em francês e está sendo dado por partes por uma revista francesa. Mas para a América não serve, sou hoje o primeiro a convir. Necessita de uma séria remodelação que nunca me animo a fazer por falta de entusiasmo. Não sei trabalhar a frio. (LOBATO, 1986, p. 110) 
Frustrados os objetivos de Lobato com seu romance, o escritor não deixaria de lado, no entanto, a viagem no tempo em sua obra. A ideia de viagem no tempo acabaria sendo utilizada por Monteiro Lobato na sua ficção infantil: O Minotauro e Os Doze Trabalhos de Hércules são exemplos disso. A mudança, porém, é nítida: se, antes, a viagem imaginada se dirigia a um futuro distante, agora a viagem tinha como destino a Grécia antiga. Sai de cena o porviroscópio, entra o pó de pirlimpimpim. Se, em $O$ choque das raças, o futuro poderia apenas ser objeto de observação, nas obras infantis, as personagens não apenas se deslocam, elas mesmas, ao passado, como também intervêm nos destinos das criaturas com que se deparam. Da inércia do mundo adulto para a ação do mundo infantil: nada mais coerente com o que passaria a pretender o escritor, que, em carta da Godofredo Rangel, em 7 de maio de 1926, desabafaria:

Ando com ideias de entrar por esse caminho: livros para crianças. De escrever para marmanjos já me enjoei. Bichos sem graça. Mas para as crianças, um livro é todo um mundo. Lembro-me de como vivi dentro do Robinson Crusoe do Laemmert. Ainda acabo fazendo livros onde as nossas crianças possam morar. Não ler e jogar fora; sim morar, como morei no Robinson e n'Os Filhos do Capitão Grant. (LOBATO, 1964, t. 2,p. 292-293)

\section{REFERÊNCIAS BIBLIOGRAFICAS}

BERGIER, Jacques. Os mestres secretos do tempo. Tradução de Edson Bini. São Paulo: Hemus, 2003, p.61-71.

CAMARGOS, Marcia, SACCHETTA, Vladimir. "Um fabulista visionário”. In: LOBATO, Monteiro. O presidente negro. São Paulo: Globo, 2008, p.18.

CARNEIRO, André. Introdução ao estudo da "science-fiction". São Paulo: Conselho Estadual de Cultura, 1967, p.109.

DIAS, Maicon Alves. A representação da realidade em O presidente negro, de Monteiro Lobato. Miscelânea, Assis, vol. 6, jul./nov. 2009, p.77. Disponível em: <http://www. assis.unesp.br/posgraduacao/letras/mis/pdf/v6/maicon.pdf>. Acesso em: 21 nov. 2011.

LAJOLO, Marisa. A figura do negro em Monteiro Lobato. Disponível em: <http://www. unicamp.br/iel/monteirolobato/outros/lobatonegros.pdf>. Acesso em: 22 jun. 2011.

LOBATO, Monteiro. A barca de Gleyre. São Paulo: Brasiliense, 1964, 2 t. . Cartas escolhidas. São Paulo: Brasiliense, 1964, 2 t. . Ideias de Jeca Tatu. São Paulo: Brasiliense, 1964, p.137-138. . Monteiro Lobato Vivo. Seleção e organização de Cassiano Nunes. Rio de Janeiro. MPM Propaganda, Record. 1986. p.72. 
Mundo da lua e Miscelânea. São Paulo: Brasiliense, 1964.

. O Choque: romance do choque das raças na América no ano de 2228. São Paulo: Companhia Editora Nacional, 1926.

MANN, George (org.) The mammoth encyclopedia of science fiction. New York: Carroll \& Graf., 2001, p. 6, apud CARDOSO, Ciro Flamarion. Ficção científica, percepção e ontologia: e se o mundo não passasse de algo simulado? In: História, Ciências, Saúde - Manguinhos. Rio de Janeiro, v. 13 (suplemento), p.17-37, outubro 2006.

MARQUES, Nelson. A(s) máquina(s) do tempo: a ficção científica tem futuro?. Cienc. Cult., São Paulo, v. 54, n. 2, out. 2002. Disponível em: <http://cienciaecultura. bvs.br/scielo.php?script=sci_arttext\&pid=Sooo9-67252002000200031\&lng=en\&nrm =iso $>$. Acesso em: 11 out. 2012.

MORRISON, Michael A. John Barrymore, Shakespearean Actor. Cambridge: Cambridge University Press, 1999.

PENNA, João Camillo. Máquinas utópicas e distópicas. In: NOVAES, Adauto (org.) Mutações: ensaios sobre as novas configurações do mundo. Rio de Janeiro: Agir, São Paulo: Edições SESC SP, 2008, p.185-216.

S. A. M. Pelos livros - H. G. Wells. Gazeta de Notícias, Rio de Janeiro, 24 de janeiro de 1902, p.1-2.

SCIENCE FICTION DICTIONARY. Introduction by Samuel Anthony Peebles. New York: Gnome Press Incorporated Publishers, 1951, p.28).

SHAW, Harry. Dicionário de termos literários. Lisboa: Dom Quixote, 1982, p.208.

SILVA, Alexander Meireles da. O admirável mundo novo da República Velha: o nascimento da ficção científica brasileira. Eutomia - Revista Online de Literatura e Linguística, Recife, ano 1, no 2, 2008, p.262-283. Disponível em: http://www.revistaeutomia.com. $\mathrm{br} /$ volumes/Ano1-Volumez/especial-destaques/O-Admiravel-Mundo-Novo-daRepublica-Velha_Alexander-Meireles-Silva.pdf Acesso em: 11 out. 2012.

TIN, Emerson. Em busca do "Lobato das cartas": a construção da imagem de Monteiro Lobato diante de seus destinatários. Tese (doutorado) - Universidade Estadual de Campinas, Instituto de Estudos da Linguagem. Orientador: Marisa Philbert Lajolo. Campinas, SP: [s.n.], 2007. 
